\title{
The Impact of Electronic Tests on Students' Performance Assessment
}

\author{
Dalia Alyahya ${ }^{1} \&$ Nada Almutairi ${ }^{2}$ \\ ${ }^{1}$ Department of Educational Technology, King Saud University, Riyadh, Saudi Arabia \\ ${ }^{2}$ King Saud University, Riyadh, Saudi Arabia \\ Correspondence: Dalia Alyahya, Department of Educational Technology, King Saud University, Riyadh, Saudi \\ Arabia.
}

Received: December 27, 2018

Accepted: January 30, 2019

Online Published: April 29, 2019

doi:10.5539/ies.v12n5p109

URL: https://doi.org/10.5539/ies.v12n5p109

\begin{abstract}
This study has aimed to measure the effect of electronic tests on the academic achievements of middle school students in Arabic course. The sample has been divided into two groups; the experimental group and the non-experimental group after using the mixed experimental method. Statistical measurements had been used before, and after, the experiment for both groups; whereas, study tools were consisted of achievements test and focus group. The results have assured the existence of statistical differences between the experimental group and non-experimental group in the (language classification) category marks. The results have shown no statistical differences on the audio comprehension, reading comprehension, writing, handwriting skills, language style, grammatical function and writing expression categories marks, which give preferences to use the electronic test rather than the traditional (pen and paper) test. The study has concluded that teachers must be encouraged to perform continuous evaluation throughout the academic semester by applying electronic tests. They must emphasize on the importance of grounding rules and regulations to apply electronic tests in the educational institutions.
\end{abstract}

Keywords: electronic test, academic achievement, electronic evolution, education technology, educational tests and standards

\section{Introduction}

Due to the digital transformation witnessed by Saudi Arabia in the Vision 2030, the interest of the Ministry of Education in adopting the use of modern technology within educational organizations of all departments has increased. This allows them to solve many educational problems, especially practiced by teachers within the campus of school when teaching lessons or assess students. Education is the core foundation on which citizens are prepared and developed (Khairi, 2009). It became an integral part of the development; therefore, an individual can benefit from its advanced materials and educational techniques. Individuals can implement them and achieve the best impact on the learning process, especially by adopting transparency and consistency. When cognitive objectives are achieved and the mechanism to access them is implemented, it will lead to the emergence of modern methods to evaluate students through electronic tests, which are considered as ideal alternative to traditional paper tests. Consequently, it saves effort and time at the highest levels of transparency when used to assess students' achievements. Assessment is the main interest in the educational process, the more an individual conduct assessment in certain course, the more burden will be on the teacher, especially in marking papers and check and review the students' answers. Al-Husseini (2013) describes the advantages of electronic test over traditional paper test using new types of questions that measure skills. It also provides instant and accurate marking of the test, measurement of the performance of students and instant feedback. Moreover, it is inexpensive, offers flexibility in conducting multiple tests, and easy for the teacher to prepare and implement through the bulk of questions.

In Arabic language course, assessment process includes three comprehensive assessments for each module as a result of implementing electronic test for a module of Arabic course curriculum in middle school. By following a specific standard schedule by the Ministry of Education, the test is created and applied in this study on a sample of the students of middle school and its impact on academic achievement is measured. The researcher believes that the electronic test will help to develop a student who has the characteristics of digital citizenship. The purpose of this study is to make educational materials with continuous assessment progress within advanced 
experimental environments and to be a successful alternative replacing the traditional tests (paper and pen). The study states the importance of electronic test and academic achievement variables in the sample of middle school due to the difficulty of the educational material. It is possible to add vitality to grammar course by teacher's strategies and methods that attract students to the material and entice them, engaging them in the process of learning, and informing them of the importance of grammar in their lives (Gad, 2003). There are still challenges that students face in understanding and applying Arabic language skills despite the efforts exerted by teachers and educational figures. This study has noticed the lack of desire of learners toward this subject because of the difficulty and the need for continuous practice until the learner masters their skills through means to understand and apply the skills of Arabic language exercises and tests. Therefore, the study of electronic tests is one of the issues that have received the attention of researchers in the field of evaluation and assessment. In this regard, the study focuses to address the impact of applying electronic tests on the academic achievement among middle school students in the Arabic language course. Similarly, the study addresses the views of middle school students about adopting electronic testing in the educational process.

The novelty of this study has been explained from its contribution to the development and activation of the role of electronic tests on a module within a course. The study has also intended to develop the role of electronic tests in raising the educational efficiency through enriching and enhancing students' academic achievement. As the study contributes to the enrichment of studies and researches in Saudi Arabia, it will allow the researcher to fulfil the lack of evidence in adopting electronic tests in the educational process, especially in middle schools. Following objectives have been proposed based on the aforementioned questions.

\subsection{Objectives of the Study}

- Determine the impact of implementing electronic tests on the achievement of academic students in middle schools in Riyadh.

- Identify the trends of middle school students towards electronic tests and make a use of their opinions to develop the procedures and mechanisms for the optimal application of electronic tests.

- Provide a theoretical basis for electronic tests in terms of their concept and importance in the educational process.

\section{Literature Review}

\subsection{Theoretical Framework}

The concept of measurement in the learning process is to collect quantitative information and observations on the measured topic, which is the numerical value scored by the student in the test and focuses on the final process (Alshaf'i et al., 2015). The concept of assessment, as defined by (Awdeh, 1985), is an organized process related to the measurement process and its results describe the characteristics and qualities, and issue judgments and decisions according to specific criteria. The purpose of assessment should be determined to identify the appropriate assessment pattern tools for information collection.

The importance of selecting and preparing appropriate assessment tools is to meet assessment requirements, which is characterized by transparency, consistency, and objectivity. Jalila's (2017) study entitled aimed to design and produce a training electronic test by means of the immediate booster method (true or false) + (scoring automatically) + (showing the correct answer) and to measure its effect on the motivation for achievement. The researcher used the experimental method to measure the motivation for achievement where the results of the study show statistical differences between the average scores of the students. Assessment report should contain complete and adequate information in such a way that decision-makers can make the appropriate judgment or choose from alternative decisions (Alkubaisi, 2015).

\subsection{Empirical Framework}

\subsubsection{Assessment Types and Their Role in Improving the Learning Process}

There are two types of assessment for improving the learning process; initial assessment and formative assessment. The purpose of initial assessment is to identify the previous experiences, knowledge, and skills of students before the beginning of the educational program to judge its validity. On the contrary, formative assessment is associated with the educational process from the beginning and on a continuous basis (Alkubaisi, 2015). In Holmes' (2015) study, student perceives their learning and engagement in response to the use of a continuous e-assessment in an undergraduate module. The study has investigated students' views on the use of weekly electronic assessments in a module, and whether this had any impact on their participation with this module compared with other module. This study was conducted on two small classes in one of the higher 
education institutions in the United Kingdom. Students responded positively to the continuous use of e-assessments and found that students' satisfaction was closely related to students' participation. Therefore, it is important to recognize that improved participation is a mean of enhancing the quality of student experience and ensuring assessments that encourage students to interact with learning. Similarly, the performance of a student is judged by comparing the performance of others to the same used criterion in the norm-referenced assessment (Alkubaisi, 2015).

Diagnostic assessment aims towards a group of learners who do not make satisfactory progress in tests and do not show progress or improvement despite the provision of special teaching procedure (Alkubaisi, 2015). Summative Assessment is another type in which learning outcomes are assessed at the end of a module, semester, study year or educational program. Modern education supports it in all phases of education. It came from the idea of democratic values that states that learners have the responsibility to work towards goals that they understand and consider worthy of their consideration (Alkubaisi, 2015).

Types of tests vary according to the above assessments where electronic tests can include a number of methodological questions presented by using a computer program in an organized manner according to a specific assessment mechanism and then presented to the student to solve it. Therefore, he can assess himself, his level of knowledge, and his understanding of the material directly (Alshafouri, 2006).

\subsubsection{Impact of Electronic Tests on Academic Achievement}

The study of Millsap (2000) was the first study to address the impact of electronic tests towards students' academic achievement. In this regard, the study has included 227 students who attend 12 classes of the Apprentice Medical Specialist Resident Course. The study has applied one-way ANOVA and t-test for analyzing the data. From the findings, the study failed to find any significant difference between electronic test administration modes and academic achievement. Similarly, Hijazi (2011) has examined the use of computer-based assessment and paper-based assessment strategy to evaluate the academic achievement of students in English grammar course. A total of 209 male and female students in Jordanian universities were selected. The results obtained using two-way ANOVA and descriptive statistics exhibit the statistically significant differences in the computer-based assessment and academic achievement of students in English grammar.

Alzubi (2015) has examined the impact of electronic exams on students' achievement in an English course. Electronic exam was assessed on 58 students and revealed that the scores of students were statistically significant on the academic achievement. An effective statistical approach exhibited significant difference between the groups of the electronic exams scores and motivation scales among Jordanian students. Basaran, Yalman, and Gonen (2016) have shown the importance of electronic assessments or tests in terms of faculty members. The study has shown that faculty members can acquire rapid results and make education better. From the perspective of students, it allow them to save time and cost, allow flexibility, increase the reliability by mitigating the mistakes made by human, provide adequate and rapid feedback, and collect the responses to the questions in the computer environment.

Harris and Al-Bataineh, (2015) have also supported the impact of electronic assessments and revealed that the tool can be of significant interest for students and teachers in improving academic achievement among institutions. Electronic tests might be the catalyst for school to assist their students for achieving at higher levels with more technology exposure for students and professional development. You (2015) has indicated that the course achievement was negatively associated with the late submission and absence of assessments. The study has also indicated a predictable increase of course achievement based on the electronic assessment scoring system.

\subsubsection{Trends Associated with Electronic Tests and Its Development}

The skills that must be taken into account are the previous computer experience, as the educational literature confirms that learners who are not familiar with the computer are unable to use it comfortably and consequently affects student's performance in electronic tests. According to Abdelaziz (2012), the attitudes of some students toward computer are particularly negative. In contrast, there is a group of students who have computers at home, and many studies have shown that familiarity with computers plays an important role in performance (Abdelaziz, 2012).

Educational researchers have focused on the subject of test anxiety in terms of computer anxiety and computer-familiarity anxiety because there is interaction between the two factors. Previous studies have shown that electronic testing contributed to reduce test anxiety. For instance, the trend towards the computer is the 
source through which the concern of computer and trend is a more comprehensive psychological concept as a mixture of beliefs and feelings while anxiety is a negative emotional response to deal with the computer (Jamea, 2014; Amer, 2008). In addition, there is a study on gender trends that shows that females are more concerned than males. The study has also shown that they are less concerned than males with training and application (Abdelhamid, 2002).

Simonson et al (1987) says that the positive trend is an important requirement for computational culture toward the computing. Khuraibah (2015) aims to measure the degree of anxiety of electronic testing in female students and determine the degree of verification of the trend towards electronic testing that vary according to both achievement (high, low) and optional preference (electronic test, paper-and-pen test). The results state that there are differences between the average grades of students who prefer electronic testing and students who prefer paper-and-pen test (emotional, cognitive and behavioral components) to the trend towards electronic testing for the electronic test.

Several studies evidently reported that the inability to revise and change the answers have a negative impact on students' performance in electronic tests (Wise \& Plake, 1989). Vispoel et al. (1992) found that applicant's ability to review and change their answers improved the performance of the applicants. It also increases the time required to perform the test, strongly favored by the applicants, and concluded that reviewable and unreviewable electronic-tests do not yield the same results. Mohammed (2014) suggests that the provision of feedback in the test environment may increase learner motivation and progress toward testing. Wise and Plake (1989) noted three basic characteristics of paper test should be taken into account when designing electronic tests. In contrast, Ahlan, Atanda, and Shehu (2014) aimed to demonstrate the impact of electronic tests on increasing the performance of academic students, their acceptability and the impact of owning a computer on the student's performance in electronic tests. The results have stated that there is a significant relationship between the use of technology in the tests and the performance of the academic students.

Several studies have examined the on-screen display of the test and its impact on the performance of the applicants. Mckee and Levinson (1990) found that the elements of display, screen size, font size, and image resolution are directly related to performance in electronic tests. One of the most important factors that may cause differences between paper and electronic tests is the interactive and size of display. The material displayed on the computer screen may not exceed $1 / 3$ of overall material that can be displayed on the paper, and reading from the screen may be directly more stressful for students than the traditional reading (Mourant et al., 1981). Electronic test in this study considers the methods of assessment in the Arabic language curriculum for the third-middle grade. The Arabic language subject is considered as integrated principle that are integrated in a single subject with a number of modules (three modules in a semester), which means that the learner has a variety of linguistic competences (listening, reading, spelling, writing, linguistic, grammar, speaking).

\section{Material and Methods}

\subsection{Research Design}

The study implements a mixed-type experimental method that combines the strengths of the quantitative and qualitative approaches of data. Data integration provides a better understanding of the problem and its primary purpose to avoid the shortcomings of both quantitative and qualitative approaches (Creswell, 2014).

\subsection{Targeted Population}

The study has selected middle-school female students who were enrolled in Arabic course in the second semester 1438-1439AH in Civic Education Middle School, Riyadh, Saudi Arabia.

\subsection{Measures}

The approach used in this study is the mixed experimental approach, which is based on two groups; experimental and control, as the two groups take the same pre- and post-tests. The independent variable is limited to the experimental group without the control, using the quantitative tool, which is a collection test. Table 1 shows the experimental design of the study to address the impact of the use of electronic tests on the academic achievement among middle school students in Arabic course. 
Table 1. Experimental design

\begin{tabular}{|c|c|c|c|c|}
\hline Group & Parity & $\begin{array}{c}\text { Independent } \\
\text { variable }\end{array}$ & Dependent variable & Test Type \\
\hline \multirow[t]{2}{*}{ Experimental } & -Previous & Electronic test & & \\
\hline & achievement & & Academic & Achievement test after studying the intended \\
\hline \multirow[t]{2}{*}{ Control } & -Age & Paper-and-pen test & achievement & module \\
\hline & -Educational stage & & & \\
\hline
\end{tabular}

A qualitative tool has been used to investigate the content of the discussion group to collect qualitative data and subject it to objective analysis to emphasize on the views of middle school students when using the electronic test in the educational process.

\subsection{Instruments}

The electronic and traditional approaches were used to measure the academic achievement. The test includes questions that measure various components (audible and reading comprehension, spelling, writing, linguistic, grammar, and writing skills). The researcher chose this classification due to its importance for measuring it under the developed Arabic curriculum.

\subsection{Data Collection}

Semi-structured interviews have been collected from the group of people from 8 to 10 individuals. The researcher asks few questions and collects responses from all members of the group. A set of open-ended discussion questions were constructed in this study with a presentation of the etiquette and methods of dialogue for effective discussion and giving a specific time to answer the questions after random selection of a group of 8 to 10 female experimental group. The researcher conducted the discussion group after the completion of the electronic test tool and provides students with their final marks.

\subsection{Data Analysis}

As the study design is based on a mixed-design approach, both quantitative and qualitative analysis tools have been adopted in this study. For quantitative data analysis, the researcher has applied statistical program for statistical analysis (SPSS) and performed eta-squared test for determining the impact of applying electronic tests on the academic achievement. In addition, paired sample t-test was performed to determine the difference between control group and experimental group in terms of linguistic patterns. For qualitative analysis, the researcher has performed a thematic analysis to present the responses and views of the interviewees in multiple themes. A total of 6 themes have been plotted and summarized in a tabular form to show the importance of applying electronic tests and its impact on the academic achievement.

\subsection{Validity and Reliability}

A pilot test has been performed on a sample of 20 to measure the validity and inter-reliability of the questionnaire for further analysis. A Cronbach alpha has been used as a measurement parameter for measuring the reliability of the questionnaire. The cronbach alpha coefficient indicates a suitable value of 0.80 , which is sufficient enough for the researcher to carry out further analysis on the sample.

\subsection{Operational Variables}

\subsubsection{Electronic Tests}

It is a copy of the traditional paper tests, but it is taken by using a computer, where students read the questions directly from the screen and answer them through input devices (mouse, keyboard, touch screen) (Wang \& Shin, 2010).

\section{Results}

\subsection{Impact of Applying Electronic Tests on the Academic Achievement}

To determine the impact of the use of the electronic test, the researcher used the significant coefficient. Table 2 shows the application of Eta-squared ( $\eta 2$ ) test for determining the impact of applying electronic tests on the academic achievement. 
Table 2. Eta-squared test results

\begin{tabular}{|c|c|c|c|c|c|c|c|c|c|}
\hline Questions patterns & Statement & No. & Average & Standard deviation & Freedom degrees & $\mathrm{T}$ & significance & $\eta^{2}$ & Impact \\
\hline \multirow{2}{*}{ Linguistic category } & Control & 21 & 2.798 & 1.28116 & \multirow{2}{*}{40} & \multirow{2}{*}{6.512} & \multirow{2}{*}{0.015} & \multirow{2}{*}{0.14} & \multirow{2}{*}{ Great } \\
\hline & Experimental & 21 & 3.560 & 0.48027 & & & & & \\
\hline
\end{tabular}

It is obvious from the table that the value of the significance between the control group and the experimental group in the linguistic patterns was 0.015 , which is less than 0.05 . Therefore, there is a difference between the experimental group averages from the control group. The value of Eta-squared for the experimental group was $0.14>0.0138$, which means that the effect of the use of the electronic test according to the type of the questions of the linguistic category was significant (Table 3 ).

Table 3. Paired Sample T-test for the grades of different question patterns

\begin{tabular}{|c|c|c|c|c|c|c|c|}
\hline Statement & Statement & No. & Average & $\begin{array}{l}\text { Standard } \\
\text { deviation }\end{array}$ & $\mathrm{T}$ & $\begin{array}{c}\text { Function } \\
\text { value }\end{array}$ & Statistical significance \\
\hline \multirow{2}{*}{ Audible comprehension } & Experimental & 21 & 3.833 & 0.32914 & \multirow{2}{*}{0.44944} & \multirow{2}{*}{1} & \multirow{2}{*}{ No statistical significance } \\
\hline & Control & 21 & 3.833 & 0.24152 & & & \\
\hline \multirow{2}{*}{$\begin{array}{l}\text { Readable } \\
\text { comprehension }\end{array}$} & Experimental & 21 & 3.798 & 0.35017 & \multirow{2}{*}{17.4122} & \multirow{2}{*}{0.07} & \multirow{2}{*}{ No statistical significance } \\
\hline & Control & 21 & 3.952 & 0.1504 & & & \\
\hline \multirow{2}{*}{ Spilling } & Experimental & 21 & 2.381 & 1.04767 & \multirow{2}{*}{0.60181} & \multirow{2}{*}{0.93} & \multirow{2}{*}{ No statistical significance } \\
\hline & Control & 21 & 2.976 & 1.19086 & & & \\
\hline \multirow{2}{*}{ Writing } & Experimental & 21 & 2.810 & 0.51177 & \multirow{2}{*}{0.53115} & \multirow{2}{*}{0.664} & \multirow{2}{*}{ No statistical significance } \\
\hline & Control & 21 & 2.881 & 0.54554 & & & \\
\hline \multirow{2}{*}{ Linguistic type } & Experimental & 21 & 2.798 & 1.28116 & \multirow{2}{*}{17.2596} & \multirow{2}{*}{0.015} & \multirow{2}{*}{$\begin{array}{c}\text { There's statistical } \\
\text { significance }\end{array}$} \\
\hline & Control & 21 & 3.560 & 0.48027 & & & \\
\hline \multirow{2}{*}{ Linguistic style } & Experimental & 21 & 2.143 & 0.76474 & \multirow{2}{*}{1.60158} & \multirow{2}{*}{0.16} & \multirow{2}{*}{ No statistical significance } \\
\hline & Control & 21 & 3.524 & 4.28216 & & & \\
\hline \multirow{2}{*}{ Grammar } & Experimental & 21 & 3.607 & 5.04391 & \multirow{2}{*}{1.54228} & \multirow{2}{*}{0.539} & \multirow{2}{*}{ No statistical significance } \\
\hline & Control & 21 & 2.905 & 1.05912 & & & \\
\hline \multirow{2}{*}{ Written communication } & Experimental & 21 & 3.905 & 0.30079 & \multirow{2}{*}{10.519} & \multirow{2}{*}{0.155} & \multirow{2}{*}{ No statistical significance } \\
\hline & Control & 21 & 4.000 & 0 & & & \\
\hline
\end{tabular}

\subsection{Views of Middle School Students about Adopting Electronic Testing}

The researcher relied on certain classifications, which were divided according to the questions. These classifications were related to the most important factors affecting the electronic test such as time factor, neutral factor in marking without being affected by markers performance, factor of computer anxiety, electronic testing anxiety and questions difficulty, factor of essayistic and objective questions, and changing answers factor. At the end of the discussion, the most prominent suggestions and views were identified on the possibility of adopting the electronic testing experience (Table 4).

Table 4. View of middle school students about adopting electronic testing

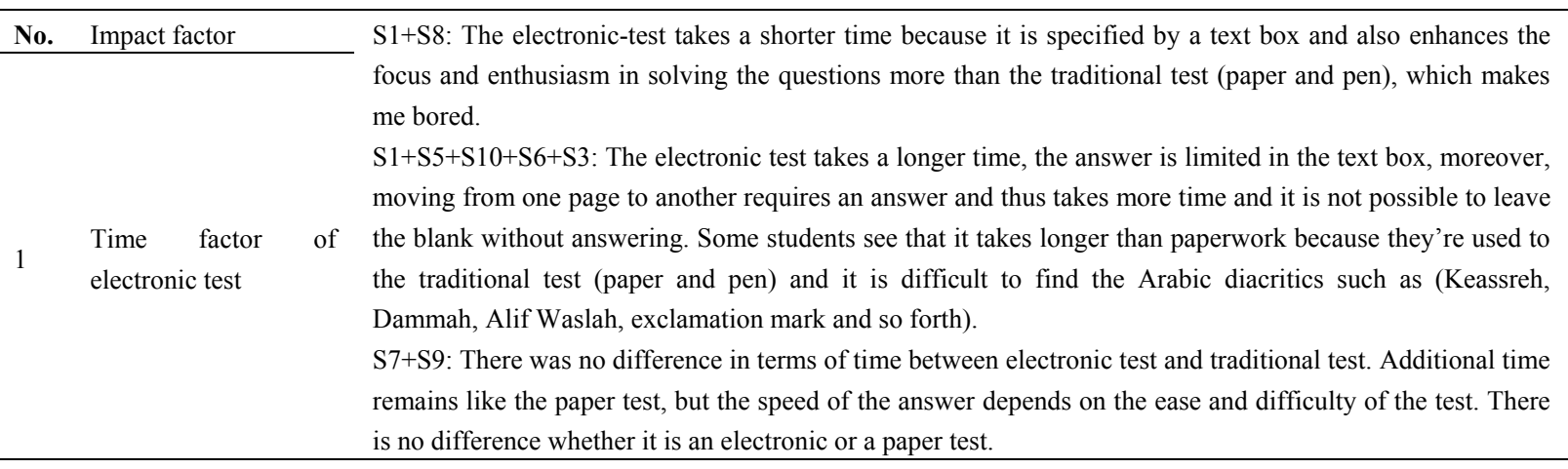


$\mathrm{S} 1+\mathrm{S} 6+\mathrm{S} 7+\mathrm{S} 10$ : Yes, it is neutral and this scares me, because it may ask for a specific answer and my answer may be wrong even if its content is true but it is written in another form. Some students hope to get their marks at the end of the test to decide whether it is neutral or not, and some believe that they did not get used to the electronic test so avoid the automatic marking, others see how easy to mark the test for the teacher, but hard for the student since they cannot answer in a simple language.

$\mathrm{S} 3+\mathrm{S} 8+\mathrm{S} 9$ : Not neutral, perhaps the reason is being uncapable to answer in detail and this makes it not neutral, especially that marking is done automatically and manually by the teacher. Others see that there is

Neutral factor in marking without being affected by markers performance

Factor of computer anxiety, electronic testing anxiety and questions difficulty no differentiation in marking process because the mark depends on how hard you have studied despite whether it's neutral or not.

$\mathrm{S} 2+\mathrm{S} 4+\mathrm{S} 5$ : There was no difference in the marking although at first there was stress but not related to the ease and difficulty of testing, but because answering was through the computer. Some believe that it requires a specific answer and only one so it came to the idea that the correction is neutral and the answer should be typical, then after the inquiry and know that the correction will be automatic and manual, the idea became clear and there was no need to be stressed. Moreover, the answer to the electronic-test is arranged and easier because no additional details can be written meaninglessly, and some students feel that it does not matter whether the electronic or paper-based marking because they will solve the test with a high confidence regardless of the nature of the marking.

S1+S6: Since the test was final there was stress from the "final test" word and not from the computer screen, and for the first time an electronic test was applied to Arabic course.

$\mathrm{S} 2+\mathrm{S} 4+\mathrm{S} 8+\mathrm{S} 10$ : There is no stress. It is normal because it is similar to the learning management system, it has been applied on the Classera platform and we all take periodic tests through it. For some students, the screen is easier and simpler and the line is clear while paper tests are harder, and some resemble a computer screen like a mobile screen and there are those who feel happy where the computer lab environment feels comfortable because the computer lab reduces anxiety and fear of testing.

$\mathrm{S} 3+\mathrm{S} 5+\mathrm{S} 7+\mathrm{S} 9$ : Yes, we are stressed at the beginning, however, over time, the situation became normal, and we also felt comfortable after reading the questions because they were clear and the design of the test is simple and beautiful, others felt stressed because it's their first time to take Arabic course test online.

$\mathrm{S} 2+\mathrm{S} 3+\mathrm{S} 8+\mathrm{S} 9+\mathrm{S} 10$ : A group of students consider that the combination of essay questions and objective questions in electronic testing is good and gives a sense of satisfaction during giving the answer. And some see that they used to both forms in Arabic course test. Others believe that the combination of the two forms

Essayistic and objective questions is good in electronic testing because the objective questions cannot be overcome without writing the solution and this is important.

$\mathrm{S} 1+\mathrm{S} 4+\mathrm{S} 5+\mathrm{S} 6+\mathrm{S} 7$ : The format of the questions in the electronic-test does not matter because some believe that studying well is good enough regardless of the format of the question, whether it is essay or objective.

$\mathrm{S} 1+\mathrm{S} 2+\mathrm{S} 3+\mathrm{S} 4+\mathrm{S} 5+\mathrm{S} 6+\mathrm{S} 7+\mathrm{S} 8+\mathrm{S} 9+\mathrm{S} 10$ : All students agreed upon that changing the answers in the electronic test is much easier than the paper test, because by a press of a button the answer is changed, and

5 Changing answers
due to the speed and ease to change answers compared to the use of pen and eraser that require effort and and time. Besides, it enhances thinking during the solution when writing the answer and return to read it again to modify it more than once.

$\mathrm{S} 1+\mathrm{S} 2+\mathrm{S} 3+\mathrm{S} 4+\mathrm{S} 5+\mathrm{S} 6+\mathrm{S} 7+\mathrm{S} 9+\mathrm{S} 10$ : All these students agreed to repeat the experiment and Arabic course test could be easy if the final test is always presented as an electronic test. In addition, it is easier and faster to extract the results. Others see it as a fun and exciting experience and a break from paper test routine.

S6+S8: There are two students who did not agree to repeat the experiment again because they're used to

Opportunity to repeat paper test and do not trust the technology because due to the interruption of communication all data may be the experiment with lost.

application of At the end of the session, a number of suggestions were made:

additional suggestions Familiarize students with the use of electronic testing in the curriculum, especially in the Arabic course test as a continuous monthly periodic test.

Provide a prior explanation of how to answer the test and not only put instructions, but practice and conduct an experiment before the test date.

The student gets the final score at the end of the test, which increases the motivation of learning.

(S) is an observation of each student participated in focus group, followed by the number of the student based on the previous table that classifies views based on student code. 


\section{Discussion}

The results of the study showed a positive effect of the electronic test on the dependent variable academic achievement in Arabic course, especially in the component "linguistic", which has a significant impact. It shows that the use of electronic testing increases the academic achievement related to the patterns of questions of linguistic component; thus, improved the academic achievement of the total score. This finding is in-line with the results of previous studies of Abdulsalam (2017), H. Manev and M. Manev (2017), and Al-Hajili (2015) in the extent of the impact of the effectiveness of the electronic test on the academic achievement for the total score. However, for the other sub-components of the test, there are no differences in scores between the two groups. This finding is opposing the findings of Zahrani (2013) specifically in the context of grammar. The sample in this study came from technological generation in which the technical culture is prevalent and is accustomed to the use of technology in general. Therefore, there was no significant difference in the functional component between paper and electronic final tests.

The study has observed that the stress associated with the students at the beginning of the test is logical and natural, where there was a slight stress at the beginning of the test in the students, but with the passage of time began to disappear. This finding is in-line with the findings of Khreibah (2015). It was found that it was their first time to take a final test online, in addition, some of the sample students cannot hold the pen and answer the (traditional test). Thus, it increases the motivation to answer the electronic test and becomes easier to deal with different types of questions.

The use of the electronic test has helped to achieve better overall scores than the traditional test, due to the ease of handling electronic question patterns and helps to implement the required electronic test better than the paper (traditional) test. The electronic testing experience has accompanied the students since they were in the fifth-grade primary, and; therefore, no doubt will result in the assessment of the capabilities of the applicants using the paper and electronic versions. The results of this study are consistent with Al-Anati (2013) in terms of difficulty in the test paragraphs. Therefore, there is no justification for concerns about the impact of each of the properties of psychometric tests. The results of this study are contrary to the findings of the study Al-Anati (2013) in terms of reading comprehension, with differences attributed to the group that underwent the traditional test (paper and pen). In this study, there were no differences in the scores of both groups for the electronic test and the traditional test (paper and pen) in the reading comprehension.

Keeping pace with the current technological era in the use of modern technologies in daily life such as mobile phones and computers in various forms, which give students the consensus to use electronic testing technology. The results of this study, as a result of the integration of technology into the experimental environment, led to improved testing environment and did not adversely affect student achievement. This is due to the fact that students are accustomed to using technology in their academic and practical life, and it is beneficial for the teacher to save time and effort and reduce the waste of paper.

The possibility of electronic marking and return to the test and the use of the electronic archive are advantages that can be poured in favor of electronic tests to the level of its impact on the scores of students as shown by the results. Similar findings have been reported with the recommendations and suggestions of the study (Khiribah, 2015), and confirmed by the results of the study (Holmes, 2015) in the positive use of electronic tests.

The electronic test is not limited to the objective questions. This study differs with the study of Jalila (2017), which confirm the impact of different design variables on the electronic test on the motivation for academic achievement with the provision of motivation and feedback immediately. The electronic test in this study included objective and essay questions. It was found that marking of the electronic test was not only automatic but also manual at the same time. However, the overall result showed an impact on the academic achievement in favor of the experimental group.

On the one hand, the positive tendency of middle school students towards electronic testing and re-experimenting is consistent with Hassan (2016) and Khuraibah (2015). The most important reason is that the electronic test provides a specific answer in a special text box that requires filling other than the traditional test (paper and pen), which is open to answer and can write additional details that are not required in the test.

\section{Conclusion}

The ability to review the answers and change them in the electronic test has a positive effect on students. It is clear through the interaction of the researcher with the students of the focus group that the electronic test provides ease to change the answers and review the questions and answers, as all of this improves the performance of the applicants. Familiarity with computers plays an important role in performance. It is clear 
through the focus group tool that students have a positive trend toward computing. The electronic test must have three basic characteristics, such as giving the student the opportunity to skip a question and answer it later, the opportunity to review previously answered questions, and the ability to change the answers. These factors affect performance in electronic tests and must be taken into account by educators. Paying attention to past experience with the computer and skills of students is not enough, but must be train on several form of electronic tests. The adoption of the electronic assessment environments makes them feel safe and fully satisfied for optimal use. The use of software in the service of the educational process reduces the material cost in the purchase of papers and inks to print the test.

\subsection{Recommendations}

In the light of study findings, this study confirms the importance of establishing rules and regulations for the application of electronic tests in educational institutions. These rules aim to emphasize the importance of employing electronic tests because of their clear role in increasing students' academic achievement to encourage the subject teachers with continuous assessments throughout the semester to apply the electronic test. It also encourages educational institutions to develop teaching and learning systems for testing environments and raising awareness in the establishment of courses and workshops related to the development of electronic test patterns. Moreover, automatic systems should be used in all the decisions to achieve the dissemination of a culture of awareness of electronic tests and their importance in the educational process of all kinds (diagnostic, structural, final).

\section{Acknowledgments}

The author is very thankful to all the associated personnel in any reference that contributed in/for the purpose of this research. Further, this research holds no conflict of interest and is not funded through any source.

\section{References}

Abdelaziz, H. A. (2012). The Effect Of Computer-mediated Instruction and Webquest on Pre-Service Business Education Teachers' self-Directed Learning Readiness and Teaching Performance. The Journal of Research in Business Education, 54, 1.

Abdelhamid, I. S. (2002). The trend towards computer: a comparative study by sex and other variables. Journal of Social Sciences, Kuwait, 30.

Ahlan, A., Atanda, B. N., \& Shehu, Y. I. (2014). Information technology enhances students' academic performance: A case of University of Ilorin. The Online Journal of Distance Education and e-Learning, 2, $15-20$.

Al-Husseini, M. (2013). Effect of training program for postgraduate students in the Faculty of Education in the design of electronic tests according to the proposed quality standards. Educational and Social Studies, Egypt, 19, 391-460.

Alzu'bi, M. (2015). The effect of using electronic exams on students' achievement and test takers' motivation in an English 101 course. In The Proceedings of Conference of the International Journal of Arts \& Sciences (pp. 207-215).

Amer, A. N. A. S. (2008). The trend toward computer and computer anxiety is structural and causal. Journal of Faculty of Education, University of Banha, Egypt, 19, 191-164.

Assaf, S. B. H. (2006). Introduction to research in behavioral sciences. 4, Riyadh: Library and publishing Obeikan.

Basaran, B., Yalman, M., \& Gonen, S. (2016). Attitude scale towards web-based examination system (MOODLE) - Validity and reliability study. Educational Research and Reviews, 11(17), 1641-1649. https://doi.org/10.5897/err2016.2850

Chriswell, J. (2014). Design Quantitative Research - Quality - Compulsory (Translation/Abdulmohsen Ayed Al Qahtani). I. Kuwait: Dar Al Masila for Publishing and Distribution.

Creswell. J. W. (2005). Educational research: planning, conducting, and evaluating quantitative and qualitative research (2nd ed.). USA: Upper Saddle River, N.J.; [Great Britain]: Pearson/Merrill Prentice Hall, c2005.

Damer, D. E., \& Melendres, L. T. (2011). "Tackling test anxiety": A group for college students. The Journal for Specialists in Group Work, 36, 163-177. https://doi.org/10.1080/01933922.2011.586016

Harris, J., \& Al-Bataineh, A. (2015, April). One to one technology and its effect on student academic achievement and motivation. In Global Learn (pp. 579-584). Association for the Advancement of 
Computing in Education (AACE).

Hassan, M. K., \& Al Mari, M. B. A. (2016). Attitudes of Faculty Members and Students of the College of Education at Najran University towards Electronic Testing: A Survey Study. Journal of Gulf and Arabian Peninsula Studies, Kuwait, 42, 19-51.

Hijazi, D. (2011). Comparison of students' performance in English grammar using cell phone-based, computer-based and paper-based testing. European Journal of Soil Science, 20(4), 613-623.

Hodgson, P. (2012). Effective formative e-assessment of student learning: A study on a statistics course, Assessment \& Evaluation in Higher Education, $215-225$. https://doi.org/10.1080/02602938.2010.523818

Holmes, N. (2015). Student perceptions of their learning and engagement in response to the use of a continuous e-assessment in an undergraduate module. Assessment \& Evaluation in Higher Education, 40(1), 1-14, https://doi.org/10.1080/02602938.2014.881978

Imam, M., Abdul Rahman, A., \& Ajili, P. (2016). Calendar and Measurement. Dar Al Ayyam for Publishing and Distribution: Jordan.

Jad, M. A. M. (2003). Learning difficulties in Arabic. I. Jordan: Dar Al Fikr Publishing and Distribution.

Khuraibah, I. M. S. (2015). The concern of the electronic test and the direction towards it in the light of both academic achievement and test preference among students of the Department of Psychology Faculty of Education. Journal of the Faculty of Education, Al-Azhar University, 162.

Kubaisi, A. W. (2015). Measurement and Evaluation Revisions and Discussions. Amman: Jarir House for Publishing and Distribution.

Manev, H., \& Manev, M. (2017). Design, Analysis and Implementation of Electronic test for Knowledge Evaluation in the course of Information Technologies for pharmaceutical Students. Cbu International Conference on Innovations in Science and Education. March, 22-24. Czech Republic. https://doi.org/10.12955/cbup.v5.1011

McKee, L., \& Levinson, E. (1990). A review of the computerized version of the Self- Directed Search. Career Development Quarterly, 38, 325-333. https://doi.org/10.1002/j.2161-0045.1990.tb00222.x

Millsap, C. M. (2000). Comparison of computer testing versus traditional paper-and-pencil testing (pp. 1-78). University of North Texas.

Ministry of Education. (2013). Lougati Alkhalidah. Teacher Guide for the Third Grade: Second Semester. Riyadh.

Mohammed, M. A. S. (2014). The impact of the electronic structural assessment environment based on the pattern of providing feedback among peers in providing programming and motivation skills towards learning, education technology (messages and research). Egypt.

Mohammed, M., Al-Qatt, M. P., \& Jameh, H. (2014). The impact of the electronic structural assessment environment based on the pattern of providing peer feedback in providing programming and motivation skills towards learning.

Mourant, R., Lakshmanan, R., \& Chantadisai, R. (1981). Visual fatigue and cathode ray tube display terminals. Human Factors, 23(5), 529-540. https://doi.org/10.1177/001872088102300503

Powell, R. A., Single H. M., \& Lloyd K. R. (1996). Focus groups in mental health research: enhancing the validity of user and provider questionnaires. International Journal of Social Psychology, 42, 193-206. https://doi.org/10.1177/002076409604200303

Shafei, p. Osman, A. And sentences. M. (2015). School curriculum, its foundations, elements, organization, development. Dammam: Al - Mutanabi library.

Simonson, M. R., Maurer, M., Montag-Torardi, M., \& Whitaker, M. (1987). Developent of a Standardized Test of computer Literacy and A computer Anxiety Index, Journal of Educational computing Research, 3, 231-247. https://doi.org/10.2190/7chy-5cm0-4d00-6jcg

Vispoel, W., Wang, T., de la Torre, R., Belier, T., \& Dings, J. (1992). How review options, administration mode and anxiety influence scores on computerized vocabulary tests. Paper presented at the Meeting of the National Council on Measurement in Education, San Francisco (ERIC Document Reproduction service, No. TMOI8547). 
Wadih, S. S. (2004). Standards of Design and Production of Electronic Testing Programs in Networking Education (Master Thesis, Faculty of Education, Helwan University).

Ward, T. J., Hooper, S. R., \& Hannafin, K. M. (1989). The effect of computerized tests on the performance and attitudes of college students. Journal of Educational Computing Research, 5, 327-333. https://doi.org/10.2190/4u1d-vqrm-j70d-jeqf

Weiss, D., \& Kingsbury, G. (1984). Application of computerized adaptive testing to educational problems. Journal of Educational Measurement, 21, 361- 375. https://doi.org/10.1111/j.1745-3984.1984.tb01040.x

You, J. W. (2015). Examining the effect of academic procrastination on achievement using LMS data in e-learning. Journal of Educational Technology \& Society, 18(3), 64.

Zahrani, A. (2013). The effect of using electronic tests in developing some grammatical skills among secondary school students in Al-Mundak Governorate (Master Thesis, Faculty of Education, Al-Baha University, Saudi Arabia).

\section{Copyrights}

Copyright for this article is retained by the author(s), with first publication rights granted to the journal.

This is an open-access article distributed under the terms and conditions of the Creative Commons Attribution license (http://creativecommons.org/licenses/by/4.0/). 